\title{
Young students posing problem-solving tasks: what does posing a similar task imply to students?
}

\author{
Hanna Palmér ${ }^{1} \mathbb{D}$. Jorryt van Bommel ${ }^{2}$
}

Accepted: 7 January 2020 / Published online: 14 January 2020

(c) The Author(s) 2020

\begin{abstract}
This paper focuses on problem solving and problem posing in mathematics education with 6-year-olds. After working on a problem-solving activity, the young students were asked to pose a similar task to a friend. This article explores how the students interpret the notion of similar. To be able to pose a problem-solving task themselves the students had to change perspective, from searching for information to providing information, and from searching for a solution to searching for a question. Also, to create a similar task the students had to reflect on the original problem-solving task. Thus, their posed tasks shed light on their interpretation of what the original problem-solving task was really about. The results show that the large majority of the students included some three-dimensional aspects from the original problem-solving task in their posed tasks. However, the questions they posed varied in terms of whether or not they included mathematical elements.
\end{abstract}

Keywords Problem solving $\cdot$ Problem posing $\cdot$ Problem-solving task $\cdot$ Early childhood $\cdot$ Preschool class $\cdot$ Threedimensional geometry

\section{Introduction}

There is a growing international consensus in policy and research that young students can possess mathematical competencies and that such knowledge bears relevance for further mathematical development in both the short and long term (Duncan et al. 2007; Perry and Dockett 2008). There is also a growing consensus that research on early mathematics ought to be conducted in the context of early mathematics education, based on questions arising from educational practice. The empirical material in this paper is from a Swedish educational design research project investigating the potential in using problem solving as a starting point for teaching mathematics in preschool class with 6-year-olds. Educational design research was chosen for this project because problem solving is a content- and context-dependent process

Hanna Palmér

hanna.palmer@lnu.se

Jorryt van Bommel

jorryt.vanbommel@kau.se

1 Linnaeus University, Vejdes Plats 7, 35195 Växjö, Sweden

2 Karlstad University, Universitetsgatan 1, 65188 Karlstad, Sweden and therefore needs to be studied in its context (Lesh and Zawojewski 2007). In this paper, one intervention from this reseach project is presented.

Educational design research does not imply a fixed method but can be regarded as a genre of inquiry in which solutions to complex educational 'problems' are developed in iterative design cycles through collaboration between researchers and practitioners (McKenney and Reeves 2012). However, the initiative for the intervention presented in this paper was not a 'problem' but rather curiosity concerning the potential of using problem solving as the starting point for teaching mathematics to young students who have not yet begun formal schooling. Problem solving as the starting point for teaching mathematics is in contrast to the results of a Swedish national inspection of mathematics teaching undertaken in 2009, which showed that mathematics education offered limited opportunities for students to develop their ability to solve problems (Swedish Schools Inspectorate 2009).

Traditionally, the focus in school mathematics has been on problem solving, even though problem posing is often emphasised in curricula as well. Also, or maybe as a consequence, research on problem posing is still in its early years (Singer et al. 2013; Cai and Hwang 2019; Cai et al. 2015). In the Swedish preschool-class curriculum, problem 
solving as well as designing and formulating problem-solving tasks, are emphasised (National Agency for Education 2017). Comparable formulations are found in curricula for early mathematics in other Nordic countries (e.g., Utdanningsdirektoratet 2013) as well as other European countries (e.g., The Stationery Office 1999).

Despite the focus on both problem solving and problem posing in the Swedish curriculum, the research project initially focused only on problem solving. Problem solving has been both a purpose and a strategy (e.g. Lesh and Zawojewski 2007); the students have been involved in problemsolving activities and have simultaneously explored new mathematical content through their involvement in these activities. Several design cycles were implemented and showed positive results regarding students' learning of mathematics (Palmér and van Bommel 2018a, 2018b; van Bommel and Palmér 2016), as well as students' feelings towards problem solving (Palmér and van Bommel 2018c). However, as both the Swedish curriculum and research have pointed out possible applications of problem posing at the elementary school level (see e.g., Ellerton et al. 2015), we found a need to expand the research project to also include problem posing. This paper focuses on the intervention in which problem posing was included in the research project for the first time, which was not until the fifth year of iterative design cycles. After working on a problem-solving activity in three-dimensional geometry, the students were asked to pose a similar task to a friend. The questions on which we report in this paper are as follows:

- How do the students interpret the notion of similar when they are asked to pose a similar task to a friend?

- What can the posed tasks reveal regarding students' learning?

The paper begins by presenting the theoretical background, including research on problem solving, problem posing, three-dimensional geometry and the sociocultural perspective of the study. Then follows a section focusing on the methodological aspects of the study. In this connection, the problem solving task on which the students worked is presented. After sections in which we present the results and analysis, the paper ends with a discussion section in which we address also the limitations of the study.

\section{Theoretical background}

\subsection{Problem solving and problem posing}

There are many different approaches to mathematics teaching, which is why mathematics education differs both between and within countries. Despite these differences, mathematics education in western European countries shares a common focus on competencies, where mathematical competence, specifically, implies "the ability to develop and apply mathematical thinking in order to solve a range of problems in everyday situations" (EU 2007, p. 8). Problem-solving tasks are tasks in which the solver needs to struggle with important mathematics (Hiebert and Grouws 2002). Struggling implies working on tasks where the mathematical ideas are understandable but where the students have not yet obtained a pre-known method for solving the tasks. According to English (2004a), young children spontaneously engage in problem-solving activities outside formal schooling. Throughout the early years of school these informal experiences ought to be expanded with a wide range of problem-solving activities (English 2004b). Similarly, Casey (2009) as well as Lesh and Zawojewski (2007) emphasise that young students need to experience and to become comfortable with problem solving. This is partly to encourage students to become problem solvers and also because strong problem-solving skills can support other elements in mathematics. Good problem solvers seem to know more mathematics, including basic skills, and they know it differently.

In the design cycle on which we focus in this paper, the students were both to solve and to pose a problem-solving task. Niss and Højgaard (2019) state that problem posing is a part of the problem-solving competence, which means that in order to become competent problem solvers, students need to encounter tasks where they both solve and pose problems. Problem posing in education, however, is not always connected to problem solving. There are, for example, studies on students posing tasks that are not connected to problem-solving tasks (e.g., English 1998; Cankoy 2014). Further, problem solving and problem posing cannot be seen as independent or isolated from the teaching and learning of other mathematical ideas and processes (Brown and Walter 2004; English and Sriraman 2010). When students pose problem-solving tasks, they operate on and modify different mathematical content. Thus, problem posing can help students to acquire an understanding of different mathematical content as well as promote new ideas (Brown and Walter 2004; Lowrie 2002; Van Harpen and Presmeg 2013).

More research has been done on problem solving than on problem posing (English 1998; English and Sriraman 2010; Singer et al. 2013; Cai and Hwang 2019; Cai et al. 2015), which is why we know more about students' ability to solve problem-solving tasks than their ability to pose such tasks. This is especially true for younger students. One exception is the research by Lowrie (2002), in which students aged 5-6 participated in a 5-week problem-posing programme. In the study, many of the students posed open-ended tasks and they were also challenged to pose a problem that a friend could solve. 
According to Brown and Walter (2004), problem posing is related to problem solving in two ways. Firstly, it is actually impossible to solve a problem-solving task without posing new questions; for example, when solving problems, we ask questions such as 'what if' or 'what would happen if'. Thus, posing questions is part of every problem-solving process. Secondly, problem posing is related to problem solving because the mathematical activity of posing problems deepens students' understanding of the mathematical content as well as their understanding of problem-solving processes (see also Lowrie 2002). Another motive for problem posing is that it makes it possible for students to realise that problem-solving tasks are created by humans. Further, when students are asked to generate a problem-solving task or to ask a question, there is no right problem-solving task to create or right question to ask. As such, problem posing can counteract the common view of one right way in mathematics. However, the created tasks and questions can differ in quality, and such aspects of quality need to be discussed with the students. Finally, a shift from problem solving to problem posing can be seen as a shift of control from others to oneself. Thus, problem posing may also promote a sense of autonomy and independence in students (Brown and Walter 2004).

Problem posing can take place before, during or after a problem-solving activity (Lowrie 2002), and in this paper we focus on problem posing that takes place after problem solving. Asking students to pose a task for a friend is one way to make problem posing meaningful for students (see, for instance, Lowrie 2002). When posing tasks, students can be asked to reformulate or to generate tasks (Lee et al. 2018). Both when generating and when reformulating, students can investigate and develop their understanding of mathematical content and ideas, but reformulation requires students to reflect more on the existing problem-solving task (Stickles 2011). In the study presented in this paper, the students were familiar with problem solving, but it was the first time they were asked to pose a problem-solving task, in this case by reformulation. To be able to pose a task to a friend, students have to change perspective; instead of answering questions they are required to pose questions, and instead of interpreting information they need to provide information. Carrillo and Cruz (2016) suggested that, when reformulating, students can be asked to pose a new task with a structure similar to that of the original problem-solving task (e.g., an open task), or they can pose a task that can be solved by using a similar method (e.g., by using a table). The students in the study presented here were not given any such explicit directions, but were instead asked to pose a similar problem-solving task. Asking students to pose a task by reformulation in this way can reveal their sense of the original problem-solving task. Thus, while posing can enrich students' learning, it also can be revealing for their teachers (Carrillo and Cruz 2016; Kwek 2015).

When analysing problem-solving tasks posed by students, different kinds of classifications are often used. For example, Cai and Hwang (2003) used the categories extensions, no extensions and other. Extensions implied that the posed task followed the structure of the original task but that it would demand more mathematical work to solve it. No extensions implied that the posed task followed the structure of the original problem and maintained the same level of difficulty. Finally, other implied that the task did not follow the structure of the original problem. Another classification was used by Leung (1997), who classified posed tasks as not a problem, non-mathematical problem, implausible mathematical problem, insufficient plausible mathematical problem and sufficient plausible mathematical problem. Not a problem implied tasks that failed to ask an answerable question, and non-mathematical problem implied tasks where the question posed fell outside the scope of mathematics. An implausible mathematical problem implied a task where the problem fell within the scope of mathematics, but where the involved data or the solution did not make sense in the context. An insufficient plausible mathematical problem implied a posed task where the problem could receive a mathematical treatment but where the data involved were insufficient to arrive at a solution. Finally, a sufficient plausible mathematical problem implied a well-formulated problem that could be solved. This category was in turn described using four subcategories (see Leung 1997 for a more detailed description).

\subsection{Three-dimensional geometry}

Knowledge of three-dimensional geometry includes not only recognising and naming but also the spatial skills of composing, decomposing and analysing the properties and features of three-dimensional shapes. Such knowledge builds a foundation for later reasoning about fractions, area and volume (Cross et al. 2009; Sarama and Clements 2009). As spatial skills have been shown to be a predictor of further mathematical achievement, working with spatial skills is important. However, when students are asked to pose tasks without starting with an existing task, spatial problems appear in only $14 \%$ of the tasks (Lowrie 2002).

Children start to develop spatial skills early, but this development is heavily dependent on children having relevant experiences (Kersh et al. 2008). In these experiences, communication and spatial activities where students need to mentally compare, hold in mind, rotate and transform objects, have proven to be highly influential (Cross et al. 2009; Kersh et al. 2008; Sarama and Clements 2009). 


\subsection{Sociocultural perspective}

In this study we take a sociocultural perspective on mathematics teaching and learning. There are a wide range of approaches within the sociocultural perspective, and even though these differ in several respects, they have in common that knowing and doing mathematics is seen as a social and cultural practice (Cobb et al. 1996; Rogoff 2003). According to sociocultural perspectives, individuals learn mathematics by participating in social and cultural practices of mathematics. The learning of mathematics is visible as changes in this participation (Borko 2004; Jakobsson, 2012; Rogoff 2003). To participate means both to absorb and to be absorbed in social and cultural practices where the physical and social context in which an activity takes place is an integral part of the activity, and the activity is an integral part of the learning that takes place within it (Putnam and Borko 2000).

Students in mathematics classrooms participate in activities within the social and cultural practice of school mathematics. School mathematics in turn derives from the social and cultural practice of mathematics, the practical and scientific knowledge and abilities of mathematics developed through history (Jakobsson 2012). In mathematics classrooms, the social and cultural practice of mathematics is transformed into curriculum content, and according to van Oers (1996), teaching mathematics in school implies making it possible for students to make sense of mathematics as it is brought to us by cultural history. Moschkovich (2002) emphasised that school mathematics not only encompasses ways of talking, acting, interacting, thinking, believing, reading and writing, but it also includes values, beliefs and points of view on a situation.

The learning of mathematics involves learning how to talk and act in the ways that the more mathematically competent people talk and act. If we, for example, want students to make sense of three-dimensional geometry we have to engage them in activities in which this content is included. By engaging in these activities the students will gradually change their participation where some aspects will be mastered and some not. Students' learning will be indicated by changes in the ways the students participate in the activities (see, e.g., Rogoff 2003; Wertsch 1998).

Based on Borko's (2004) use of sociocultural theory, learning to solve and pose problems is a process of increasing participation in the practice of problem solving and problem posing and, through that participation, becoming knowledgeable in and about problem solving and problem posing (see also Lowrie 2002). The students in the study presented here had been frequently participating in problem-solving activities. The focus of this paper is on the part of our research when the students are introduced to the activity of problem posing, an activity in which they had not participated before. Letting the students take part in problem-posing activities can promote learning (see, e.g., van Oers 1996; Lowrie 2002). The addition of problem posing may activate, trigger, or drive thinking and actions in new directions and expand the students' participation in the social and cultural practice of school mathematics (see, e.g., Jakobsson 2012). When participating in a problem-posing activity, the students need to talk and act in a slightly different way than they do when participating in problem-solving activities. Further, when being asked to create a similar task for a friend to solve, the students have to reflect on the original problem-solving task (Stickles 2011), and thus their posed task may reveal how they interpret what the original task was really about (Carrillo and Cruz 2016).

\section{Method}

The intervention presented here was carried out in three preschool classes. Preschool class is a year of schooling that Swedish children attend the year before formal schooling begins when students are 7 years old, in order to facilitate a smooth transition between preschool and formal schooling. Until 2018, preschool class was optional (however, approximately $98 \%$ of all Swedish 6-year-olds attended), but now it is obligatory for all Swedish children to attend preschool class. Thus, preschool class is part of the formal education system and has a curriculum that includes several mathematics-related goals. These are not goals that students are expected to attain, but they provide a focus for education where each preschool class teacher can choose the teaching approaches most appropriate for the class's own setting.

\subsection{Selection of students}

The selection of the three preschool classes was based on the teachers' interest in participating. The four teachers working in these three preschool classes were educated as preschool teachers, which implies that they completed a 3-year university course in preschool teacher education. These teachers had already participated in several of the previous design cycles and hence were familiar with problem solving as well as educational design research and the aim of the study. They had implemented the problem-solving task on three-dimensional geometry several times before in other preschool classes, but problem posing was new for them. Altogether, 27 students from the three preschool classes participated in the design cycle. In accordance with the Swedish Research Council's (2017) ethical guidelines, the students' guardians were informed about the study and they approved their children's participation. 


\subsection{The problem-solving and the problem-posing lessons}

The intervention was divided into two lessons, one on problem solving and one on problem posing. Even though the focus of the paper is on the second lesson on problem posing, the lesson on problem solving is also presented here as it provides the basis for the second lesson.

In the first lesson on problem solving the students were to explore a three-dimensional composite shape, first viewing it as a two-dimensional picture and then constructing it as a three-dimensional building with blocks. Firstly, a picture of a building constructed with cubes (Fig. 1) was shown to the students and they were asked 'How many blocks will you need to build the building?'.

Based on the teachers choice of pictures, two preschool classes worked with the building on the left and one preschool class with the building on the right in Fig. 1.

In order to determine the number of blocks needed for the building, the students had to imagine the building from different perspectives. To do this the students needed to use spatial visualisation, which implies generating an image of an object and transforming and operating on this image (Sarama and Clements 2009). Besides spatial visualisation,
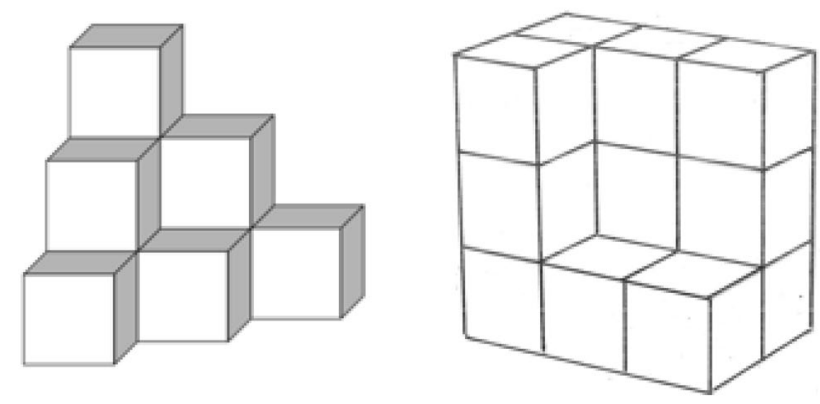

Fig. 1 Pictures of the buildings. (The building to the left is taken from https://ncm.gu.se/kangaru.) limited counting is required $(1,2,3 \ldots)$. Addition can be used, for example, $3+2+2+1+1+1$ as adding one block at the time, or $6+4$ as adding six blocks in the front and four blocks in the back. After being asked how many blocks they need to build the building based on the picture, the students were asked to build it with blocks. The task then became more explorative as the students could visualise the building from different perspectives. To close the problemsolving lesson, the concept of 'hidden blocks' was considered in a whole-class discussion and the students explored which cubes of their buildings are visible from different perspectives.

In the second lesson, the students were reminded of the building task they had worked on in the previous lesson and then they were asked to pose a similar task to a friend. The students were free to use blocks if they wanted to, but no specific instructions were given about how to design the task they would pose. In accordance with the socio-mathematical norms (Yackel and Cobb 1996) in these preschool classes, students could choose to work alone or with one or more classmates. Each student or group of students posed one task. The teachers helped the students to document the tasks they posed. Paper-and-pen work as well as digital photos taken by the students of the buildings constructed were collected.

\subsection{Framework for classification of the tasks posed by the students}

In the previous section on problem solving and problem posing, different ways to classify students' posed tasks used in previous studies were presented. Neither of these classifications could be used unmodified in this study, but the scheme for dealing with reformulated tasks by Carrillo and Cruz (2016) was the basis for the scheme used in this study (Fig. 2). Thus three aspects were the focus of the analysis: (1) the level of difficulty (hidden blocks or not); (2) the structure of the task (alike or different question); and (3) the

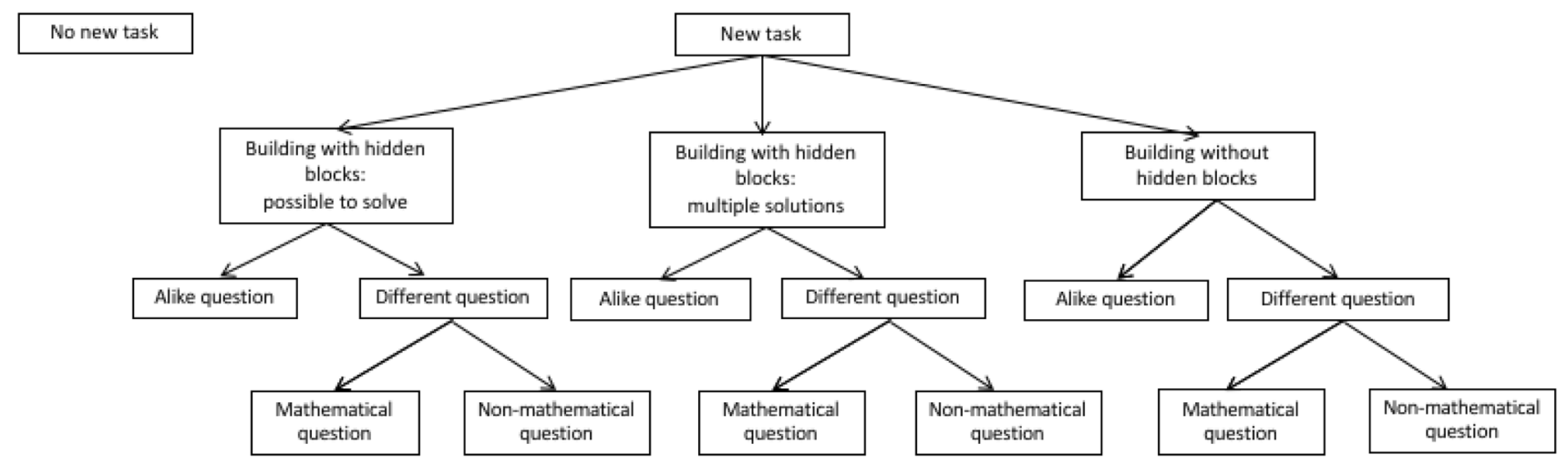

Fig. 2 Classification scheme for analyzing tasks posed by students 
connection between the task and mathematics (mathematical or non-mathematical question). The last aspect was included only for questions that were different, as a question that was alike implied a question with mathematical content since the original question was a mathematical one.

\section{How do the students interpret similar when they are asked to pose a similar task?}

In the first lesson on problem solving, one student (out of the 27) initially gave a correct answer to the question 'How many blocks will you need to build the building?' Some of the answers from the other students indicated that they realised that there were more blocks than the visible ones. After building with blocks, all students explored the need for more blocks than the visible ones, and hidden blocks from different perspectives were explored in a whole-class discussion.

In the next lesson the students were to pose similar tasks. In this section, these tasks are presented based on the classification in Fig. 2, following the order from left to right: $n o$ new task; buildings with hidden blocks, possible to solve; buildings with hidden blocks, multiple solutions; building without hidden blocks; and their subcategories alike or different question. Each student, or group of students, posed one task resulting in 15 different tasks. All of these tasks involved a photo of a building built with blocks. None of these buildings was exactly like the building the students had worked on in the original problem-solving task.

All but one student posed new tasks to be solved by a friend. The student who did not do so built a building with blocks but then said that it was not possible to pose a question.

Twelve of the 15 posed tasks were classified as buildings with hidden blocks, possible to solve. Thus, when asked to create a similar task, a large majority of the students focused on the three-dimensional aspects of the building (examples in Fig. 3).

In half of these 12 tasks (buildings with hidden blocks, possible to solve) a question focusing on the number of blocks in the building was posed; thus it was a question like the one in the original problem-solving task. Sometimes the original question was slightly rephrased but the core was kept, for example, 'How many blocks are there?' and 'How many blocks are there in our building?' The other half of these 12 tasks did not focus on the total number of blocks in the building as the question in the original problem-solving task did. Only one of these six questions was a mathematical question: 'How deep is the hole if the building has 42 blocks?' (see Fig. 4).

The students posing the task in Fig. 4 had thus created a slightly different question, albeit one that still focused on the three-dimensional aspects of the building. The other five questions were not about mathematics; they included, for example, the questions 'What have we built?', 'How do you make it fall?' and 'How can you make it speak?' These students focused on three-dimensional aspects when building and photographing their buildings, but their questions did not take these aspects of the buildings into consideration.

Two of the 15 posed tasks were classified as buildings with hidden blocks, multiple solutions (see example in Fig. 5). When asked to create a similar task, these students did focus on the three-dimensional aspects of the building but they did not create a new task that-as in the original task-was possible to solve by 'counting hidden blocks'. Both of these new tasks had a question that focused on the number of blocks in the buildings as in the original problem-solving task. However, because of the way the students had photographed their buildings, their tasks had multiple solutions.
Fig. 3 Examples of buildings with hidden blocks, possible to solve
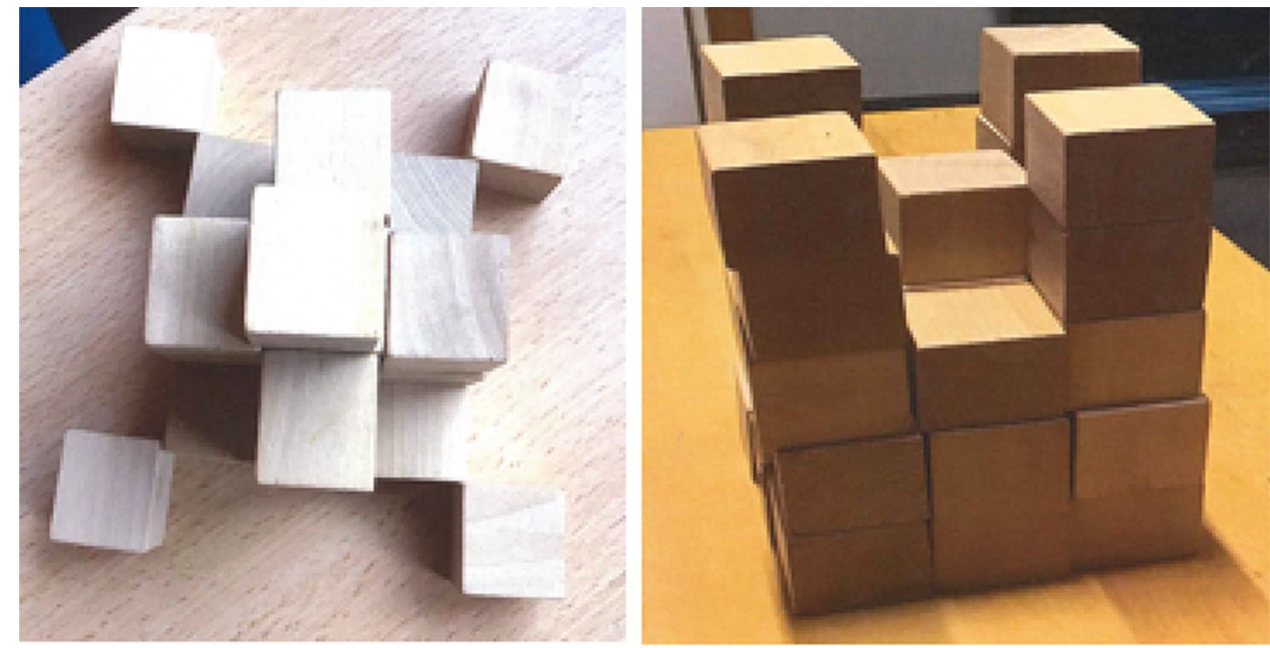


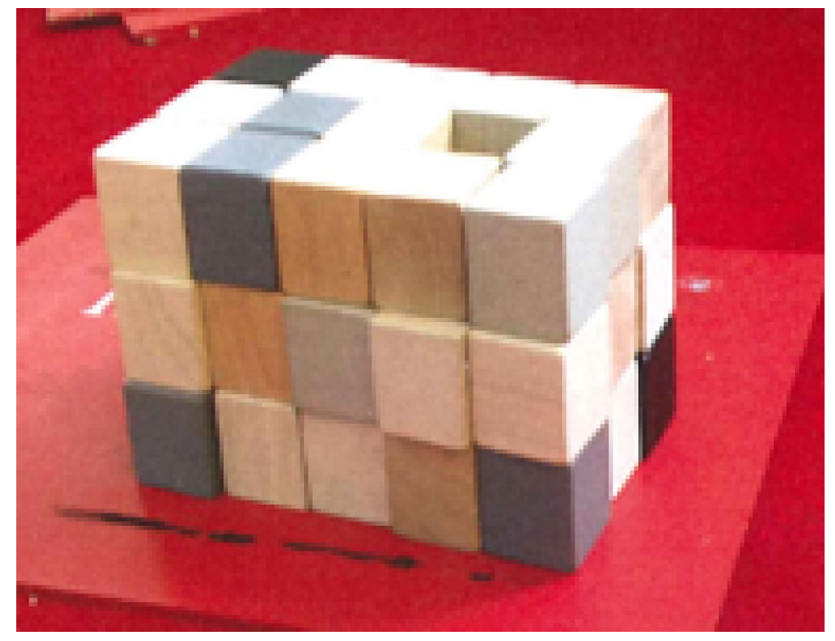

Fig. 4 Example of building with hidden blocks, possible to solve; where a mathematical question that did not focus on the total number of blocks in the building was posed

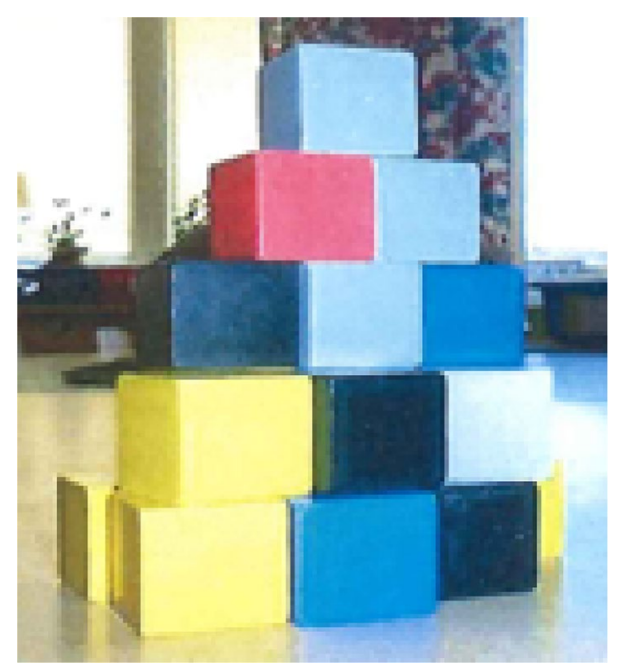

Fig. 5 Example of a building with hidden blocks, multiple solutions

One of the 15 posed tasks was classified as a building without hidden blocks (Fig. 6). The question asked about this building was an alike question focused on the number of blocks in the building: How many blocks are there?-there are no blocks behind [the building].

To summarise, almost all students focused on the threedimensional aspects of the building in the original problem-solving task when they were to pose a similar problem-solving task. This was evident in how they built and photographed their buildings, where 12 of the 15 posed tasks were classified as buildings with hidden blocks, possible to solve and two as buildings with hidden blocks, multiple solutions. However, the students who built and photographed the building classified as building without hidden

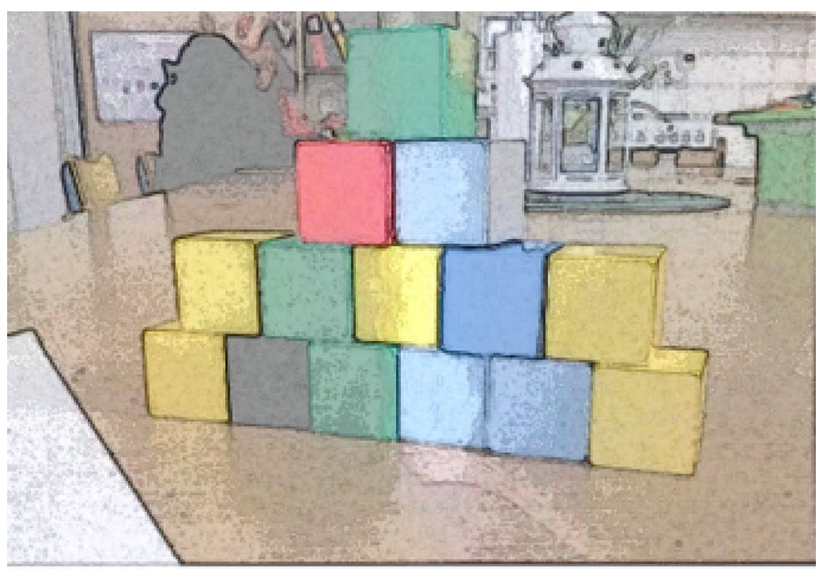

Fig. 6 Example building without hidden blocks (the picture is shaded to avoid showing students in the background)

blocks also referred to the three-dimensional aspects of the original problem-solving task when, in their posed question, they wrote 'there are no blocks behind'. Six of the 15 posed questions focused on the number of blocks in the buildings, as in the original problem-solving task. Only one question was classified as a different mathematical question while the other different questions were classified as non-mathematical. Thus, for some of the students, posing a similar task included both a similar building and a similar question, while similar for others included only a similar building. Only one group of students posed a similar question but not involving a three-dimensional building.

\section{What can the posed tasks reveal regarding students' learning?}

Based on the sociocultural perspective, the learning of mathematics involves learning how to talk and act in the ways that more mathematically competent people talk and act (see, e.g., Rogoff 2003; Wertsch 1998). The students in this study had been frequently participating in problem-solving activities, but this was the first time they participated in a problemposing activity. When participating in the problem-posing activity, the students needed to talk and act in a slightly different way than they did in problem-solving activities. Also, when asked to create a similar task for a friend to solve, the students had to reflect on the original problem-solving task (Stickles 2011). The students' interpretation of similar thus indicates their perspective (Carrillo and Cruz 2016) on the three-dimensional geometry problem-solving activity they had worked on previously.

Based on the students' work on the original problemsolving task, three-dimensional aspects in two-dimensional pictures seem to have been a quite new experience for them. 
Then, when asked to pose a similar task, all students built a building with blocks, and a large majority of these buildings were photographed in a way that focused on threedimensional aspects. This indicates that the students had made sense of some of the three-dimensional aspects of the original problem-solving task.

The questions posed by the students varied in terms of whether or not they included mathematical aspects. Only one of the questions that was classified as a mathematical question did not ask for the number of blocks. Thus, the most common mathematical question was one that was almost identical to the question in the original problem-solving activity, indicating that these students were talking and acting in exactly the same way as they did in the original problem-solving activity. These students seem to have made sense of both the three-dimensional aspects in the original problem-solving task and the features of the original task design. Five questions were not classified as mathematical questions. These questions were classified as buildings with hidden blocks, possible to solve indicating that these students had made sense of some of the three-dimensional aspects in the original problem-solving task but not all features of the original task design.

\section{Discussion and limitations}

More research has been done on problem solving than on problem posing (English and Sriraman 2010; Singer et al. 2013; Cai and Hwang, in press; Cai et al. 2015), which is why we know more about students' ability to solve problemsolving tasks than their ability to pose such tasks. This is especially true for students as young as the students in this study. When working on problem posing (and problem solving) with 6-year-olds in Sweden, it cannot be assumed that the students are able to read or write. Thus the problemposing activities have to be designed in a way that makes it possible for the students to participate even if they have not yet learnt those skills. As mentioned, the overall purpose of the whole study, not just the design cycle presented in this paper, was to investigate the potential in using problem solving as the starting point for teaching mathematics in early childhood education. Previous design cycles have shown positive results regarding students' learning of mathematics (Palmér and van Bommel 2018a, b; van Bommel and Palmér 2016) as well as students' feelings towards problem solving (Palmér and van Bommel 2018c). The design cycle presented here was the first time problem posing was included in the study, and it was the first time these teachers and students worked on problem posing. Even though only three preschool classes with 27 students were involved, the results indicate that students who are used to problem solving can quite unproblematically participate in problem posing as well. Maybe this can be explained by the close connection between problem solving and problem posing emphasised by Brown and Walter (2004), where all problem-solving processes actually involve problem posing.

Problem posing can take place before, during or after a problem-solving activity (Lowrie 2002), and in this paper we focused on problem posing that takes place after problem solving. When asked to pose a task that is similar to another one, students may think they are to pose a task based on a building similar to the one in the original problemsolving task, or they may think they are to ask a question similar to the one in the original task, or both. Even though Brown and Walter (2004) emphasised that there is no right task to create or right question to ask in problem posing, the posed tasks and questions can differ in quality. There is a big difference between building and photographing a three-dimensional building and then asking 'How do you make it fall?' and asking 'How many blocks are there in our building?' Such aspects of quality can be discussed with the students to prevent future posed questions from falling into Leung's (1997) categories of non-mathematical problems, implausible mathematical problems or insufficient plausible mathematical problems. This may be realised by having the students share and discuss their posed questions just as the students shared and discussed their solutions to problemsolving tasks.

Maybe as a result of how the problem-posing activity was framed (create a similar task), only one of the questions posed by the students extended the question in the original problem-solving task (Fig. 4). However, even if there was only one extended question posed by the students, the fact that they were working on problem posing may have deepened their understanding of three-dimensional geometry. Even if they did not expand on the original question, by posing problems, the students were still required to use and elaborate on the mathematical content in the original problem-solving task.

Finally, there are some limitations to this study. As problem solving is a content- and context-dependent process (Lesh and Zawojewski 2007) and this study includes only four teachers and 27 students, there are several limitations on the possibility of making generalisations. The teachers in the study were experienced in teaching problem solving, which may have influenced their teaching on problem posing. Even though they had not taught a lesson focused on problem posing before, such a lesson has several similarities to a lesson on problem solving. Also, the students were familiar with problem solving, which may have influenced their participation in the problem-posing activity. Based on the positive results from this first design cycle on problem posing, the problem-posing part of the intervention will be further developed and implemented in further preschool classes, hopefully providing more information on the conditions 
required to implement problem posing with students at this young age.

Acknowledgements Open access funding provided by Linnaeus University. We would like to thank the preschool class teachers Gunilla, Kristina, Lena and Åsa for their collaboration during the study. We would also like to thank our reviewers for valuable comments to the paper.

Open Access This article is licensed under a Creative Commons Attribution 4.0 International License, which permits use, sharing, adaptation, distribution and reproduction in any medium or format, as long as you give appropriate credit to the original author(s) and the source, provide a link to the Creative Commons licence, and indicate if changes were made. The images or other third party material in this article are included in the article's Creative Commons licence, unless indicated otherwise in a credit line to the material. If material is not included in the article's Creative Commons licence and your intended use is not permitted by statutory regulation or exceeds the permitted use, you will need to obtain permission directly from the copyright holder. To view a copy of this licence, visit http://creativecommons.org/licenses/by/4.0/.

\section{References}

Borko, H. (2004). Professional development and teacher learning: Mapping the terrain. Educational Researcher, 33(8), 3-15.

Brown, S. I., \& Walter, I. M. (2004). The art of problem posing (3rd edition). London: Lawrence Erlbaum Associates Publishers.

Cai, J., \& Hwang, S. (2003) A perspective for examining the link between problem posing and problem solving. In N. A. Pateman, B. J. Dougherty, \& J. T. Zilliox (Eds.), Proceedings of the Joint Annual Meeting of the PME and PME/NA. Honolulu, HI: University of Hawaii, July 13-18 (Vol. 3, pp. 103-110).

Cai, J., \& Hwang, S. (2019). Learning to teach through mathematical problem posing: Theoretical considerations, methodology, and directions for future research. International Journal of Educational Research.

Cai, J., Hwang, C., Jiang, C., \& Silber, S. (2015). Problem-posing research in mathematics education: Some answered and unanswered questions. In F. M. Singer, et al. (Eds.), Mathematical problem posing: From research to effective practice (pp. 3-34). New York: Springer.

Cankoy, O. (2014). Interlocked problem posing and children's problem posing performance in free structured situations. International Journal of Science and Mathematics Education., 12(1), 219-238.

Carrillo, J., \& Cruz, J. (2016). Problem-posing and questioning: Two tools to help solve problems. In P. Felmer, E. Pehkonen, \& J. Kilpatrick (Eds.), Posing and solving mathematical problems: Advances and new perspectives (pp. 23-36). New York: Springer.

Casey, B. (2009). Applying developmental approaches to learning math. In O. A. Barbarin \& B. H. Wasik (Eds.), Handbook of child development and early education: Research to practice (pp. 478-498). New York: The Guilford Press.

Cobb, P., Jaworski, B., \& Presmeg, N. (1996). Emergent and sociocultural views of mathematical activity. In L. P. Steffe, P. Nesher, P. Cobb, B. Sriraman, \& B. Greer (Eds.), Theories of mathematical learning (pp. 3-20). New York: Routledge.

Cross, C. T., Woods, T. A., \& Schweingruber, H. (2009). Mathematics learning in early childhood: Paths toward excellence and equity. Washington DC: National Research Council of the National Academics.
Duncan, G. J., Dowsett, C. J., Claessens, A., Magnuson, K., Huston, A. C., Klebanov, P., et al. (2007). School readiness and later achievement. Developmental Psychology, 43, 1428-1446.

Ellerton, N. F., Singer, F. M., \& Cai, J. (2015). Problem posing in mathematics: Reflecting on the past, energizing the present and foreshadowing the future. In F. M. Singer, et al. (Eds.), Mathematical problem posing: From research to effective practice (pp. 547-556). New York: Springer.

English, L. (1998). Problem posing within formal and informal contexts. Journal for Research in Mathematics Education, 29(1), 83-106.

English, L. (2004a). Mathematical and analogical reasoning in early childhood. In L. English (Ed.), Mathematical and analogical reasoning of young learners (pp. 1-22). New Jersey: Lawrence Erlbaum Associates.

English, L. (2004b). Promoting the development of young children's mathematical and analogical reasoning. In L. English (Ed.), Mathematical and analogical reasoning of young learners (pp. 201-213). New Jersey: Lawrence Erlbaum Associates.

English, L., \& Sriraman, B. (2010). Problem solving for the 21 st century. In B. Sriraman \& L. English (Eds.), Theories of mathematics education: Advances in mathematics education (pp. 263-283). Berlin: Springer.

EU., (2007). Key competences for lifelong learning: European reference framework. Luxemburg: EU.

Hiebert, J., \& Grouws, D. A. (2002). The effects of classroom mathematics teaching on students learning. In F. K. Lester (Ed.), Second handbook of research on mathematics teaching and learning (pp. 371-404). Charlotte: National Council of Teachers of Mathematics and Information Age Publishing.

Jakobsson, A. (2012). Sociokulturella perspektiv på lärande och utveckling Lärande som begreppsmässig precisering och koordinering. Pedagogisk Forskning i Sverige, 17(3-4), 152-170.

Kersh, J., Casey, B. M., \& Mercer Young, J. (2008). Research on spatial skills and block building in girls and boys. In O. N. Saracho \& B. Spodek (Eds.), Contemporary perspectives in early childhood education (pp. 233-251). Charlotte, NC: Age Publishing.

Kwek, M. L. (2015). Using problem posing as a formative assessment tool. In F. M. Singer, et al. (Eds.), Mathematical problem posing: From research to effective practice (pp. 273-292). New York: Springer.

Lee, Y., Capraro, R. M., \& Capraro, M. M. (2018). Mathematics teachers' subject matter knowledge and pedagogical content knowledge in problem posing. International Electronic Journal of Mathematics Education, 13(2), 75-90.

Lesh, R., \& Zawojewski, J. (2007). Problem solving and modelling. In F. K. Lester (Ed.), Second handbook of research on mathematics teaching and learning (pp. 763-799). Charlotte: National Council of Teachers of Mathematics and Information Age Publishing.

Leung, S. S. (1997). On the role of creative thinking in problem posing. ZDM-The International Journal on Mathematics Education, 97(2), 48-52.

Lowrie, T. (2002). Designing a framework for problem posing: Young children generating open-ended tasks. Contemporary Issues in Early Childhood, 3(3), 354-363.

McKenney, S., \& Reeves, T. (2012). Conducting educational design research. London: Routledge.

Moschkovich, J. (2002). A situated and sociocultural perspective on bilingual mathematics learners. Mathematical Thinking and Learning, 4(2-3), 189-212.

National Agency for Education. (2017). Curriculum for the primary school, preschool class and leisure time centre 2011. Stockholm: National Agency for Education. 
Niss, M., \& Højgaard, T. (2019) Mathematical competencies revisited. Educational Studies in Mathematics, (online 18 June 2019) https ://doi.org/10.1007/s10649-019-09903-9.

Palmér, H., \& van Bommel, J. (2018a). The role of and connection between systematization and representation when young children work on a combinatorial task. European Early Childhood Education Research Journal, 26(4), 562-573.

Palmér, H., \& van Bommel, J. (2018b). Problem solving in early mathematics teaching: A way to promote creativity? Creative Education, 9, 1775-1793.

Palmér, H., \& van Bommel, J. (2018c). Young students' feelings towards problem solving tasks: What does "success" imply? In B. Rott, G. Törner, J. Peters-Dasdemir, A. Möller, \& Safrudiannur (Eds.), Views and beliefs in mathematics education (pp. 69-77). Cham: Springer.

Perry, B., \& Dockett, S. (2008). Young children's access to powerful mathematical ideas. In L. D. English (Ed.), Handbook of international research in mathematics education (pp. 75-108). New York, NY: Routledge.

Putnam, R. T., \& Borko, H. (2000). What do new views of knowledge and thinking have to say about research on teacher learning? Educational Researcher, 29(1), 4-15.

Rogoff, B. (2003). The cultural nature of human development. Oxford: Oxford University Press.

Sarama, J., \& Clements, D. H. (2009). Early childhood mathematics education research: Learning trajectories for young children. New York: Routledge.

Singer, F. M., Ellerton, N., \& Cai, J. (2013). Problem-posing research in mathematics education: New questions and directions. Educational Studies in Mathematics., 88(1), 1-7.

Stickles, P. (2011). An analysis of secondary and middle school teachers' mathematical problem posing. Investigations in Mathematics Learning, 3(2), 1-34.
Swedish Research Council. (2017). Good custom in research. Stockholm: Vetenskapsrådet.

Swedish Schools Inspectorate (2009). The teaching of mathematics: The content and the effectiveness of the education. Kvalitetsgranskning rapport 2009:5. Stockholm: Skolinspektionen.

The Stationery Office. (1999). Primary school curriculum: Mathematics. Dublin: The Stationery Office.

Utdanningsdirektoratet (2013). Læreplan i matematikk fellesfag. https ://data.udir.no/k106/MAT1-04.pdf.

van Bommel, J., \& Palmér, H. (2016). Young children exploring probability: With focus on their documentations. Nordic Studies in Mathematics Education, 21(4), 95-114.

Van Harpen, X. Y., \& Presmeg, N. C. (2013). An investigation of relationships between students' mathematical problem-posing abilities and their mathematical content knowledge. Educational Studies in Mathematics., 83(1), 117-132.

van Oers, B. (1996). Learning mathematics as a meaningful activity. In L. P. Steffe, P. Nesher, P. Cobb, B. Sriraman, \& B. Greer (Eds.), Theories of mathematical learning (pp. 3-20). New York: Routledge.

Wertsch, J. V. (1998). Mind as action. New York, NY: Oxford University Press.

Yackel, T., \& Cobb, P. (1996). Sociomathematical norms, argumentation, and autonomy in mathematics. Journal for Research in Mathematics Education, 27(4), 458-477.

Publisher's Note Springer Nature remains neutral with regard to jurisdictional claims in published maps and institutional affiliations. 